\title{
Effect of Pyrazole as Nitrogenous Dopant on the Electrical Conduction of a New Polymer Blend Electrolyte System
}

\author{
J. IDA* and S.AUSTIN SUTHANTHIRARAJ \\ Department of Energy, University of Madras, Guindy Campus, Chennai-600 025, India \\ ida.jebaraj@yahoo.com
}

Received 22 June 2015 / Accepted 12 July 2015

\begin{abstract}
New solvent-free polymer blend electrolyte thin film specimens consisting of poly (ethylene oxide) (PEO)/polyvinyl pyrrolidine (PVP) were obtained by means of addition of potassium iodide, $\mathrm{KI}$ and iodine, $\mathrm{I}_{2}$ and incorporated with pyrazole as the dopant material using solution casting technique. The freshly-prepared films were structurally examined using x-ray diffraction (XRD) analysis 111 as an enhanced ionic conductivity $(\sigma)$ behavior was characterized by employing complex impedance analysis resulting in $8.46 \times 10^{-6} \mathrm{Scm}^{-1}$ at room temperature. The occurrence of complexation of the pyrazole with the chosen polymer blend has been confirmed by the Fourier transform infrared spectroscopy (FTIR) while differential scanning calorimetric (DSC) analysis has suggested the feasibility of complete miscibility of these polymeric systems.
\end{abstract}

Keywords: Solid polymer electrolytes, Nitrogenous compound, Pyrazole

\section{Introduction}

Fabrication of new materials suitable for various device applications such as batteries, sensors, fuel cells, solar cells, etc., has been gaining a lot of attention in recent years. In this context,one of the much progressed fields involves solid-state electrochemical devices based on polymer electrolytes, which efficiently over come many disadvantages that are present in those devices based on liquid electrolytes in terms of aspects dealing with safety, geometrical flexibility, ease of fabrication, cost-effectiveness, packaging, light weight and slimness $^{1}$. Poly (ethylene oxide) (PEO) has been recognized as one of the versatile polymeric systems because of its arrangement for an effective interaction of the free electron pair on the oxygen with alkali metal cations however, PEO is known to exhibit high degree of crystallinity which reduces in turn the ionic conductivity that may considerably affect its practical application in pure form. To enhance the amorphous phase within PEO certain degree of disorder has to be introduced into the original structure and the same can be achieved by appropriate blending of two polymers ${ }^{2}$. In the present study PEO has been considered as the primary polymer and PVP as the secondary polymer which is highly 
amorphous in nature and contributes an easy processability. Further an attempt has also been made to study the detailed structural and thermal characteristics behavior of the chosen blended polymer on the addition of nitrogen-containing dopant material namely pyrazole as well.

\section{Experimental}

Polyethylene oxide (PEO) $\left(\mathrm{M}_{\mathrm{w}}=5 \times 10^{6} \mathrm{~g} / \mathrm{mol}\right)$ and poly vinyl pyrrolidone (PVP) $\left(\mathrm{M}_{\mathrm{w}}=40,000\right.$ $\mathrm{g} / \mathrm{mol}$ ) purchased from Sigma Aldrich (USA) and potassium iodide (KI), iodine $\left(\mathrm{I}_{2}\right)$, acetonitrile, pyrazole procured from Merck (India) were used as the starting materials for the synthesis of blended polymeric systems during the course of the present endeavor.

\section{Synthesis of blended polymer electrolyte}

Initially $0.27 \mathrm{~g}$ of PEO and $0.03 \mathrm{~g}$ of PVP was dissolved in acetonitrile. Successively $0.1 \mathrm{M}$ of KI, $0.05 \mathrm{M}_{\text {of }} \mathrm{I}_{2}$ and $0.03 \mathrm{M}$ of pyrazole, were added to the blended polymer matrix and stirred at a temperature of $343 \mathrm{~K}$ for $3 \mathrm{~h}$ to form a homogenous liquid electrolyte The polymer electrolyte thus obtained is cast into thin films by casting them onto a glass petridish and vacuum dried in oven at $315 \mathrm{~K}$ for $19 \mathrm{~h}$.

\section{Characterization}

To determine the ionic conductivity of the synthesized thin films at room temperature, complex impedance analysis was used. The samples are placed in between a pair of stainless steel electrodes and the impedance analysis was carried out at room temperature using a computer-controlled Hewlett-Packard model HP4284A Precision LCR Meter in the frequency range $1 \mathrm{MHz}-20 \mathrm{~Hz}$. The room temperature X-ray diffraction pattern for each specimen was recorded using a Siefert Model SF60 X-ray diffraction with step size of $0.02^{\circ}$. The differential scanning calorimetric (DSC) analysis was performed by employing NETZSCH DSC 200F3 system under $\mathrm{N}_{2}$ atmosphere at a heating and cooling rate of $10{ }^{\circ} \mathrm{C} / \mathrm{min}$. Fourier transform infrared (FTIR) spectra were recorded using a Bruker TENSOR 27 FTIR spectrometer at ambient condition.

\section{Results and Discussion}

Impedance analysis

The electrical conductivity data for the samples were determined using the complex impedance plots obtained in the form of Nyquistplot exhibiting a high frequency semi-circle and a low frequency spike. The conductivity of the sample has been evaluated using the formula,

$$
\sigma=\frac{t}{R_{b A}}
$$

Where' $t$ ' is the thickness of the film in $(\mathrm{cm})$, ' $R_{b}$ 'the bulk resistance of the film $(\Omega)$ and 'A' is the surface area in $\left(\mathrm{cm}^{2}\right)$ of contact of the film with the electrode. The thickness and area of the specimen are $0.6 \times 10^{-3} \mathrm{~cm}$ and $1 \mathrm{~cm}^{2}$ respectively. The value of bulk resistance $R_{b}$ has been determined from the point of intercept of Nyquist plot on the real axis using the $\mathrm{z}$ simsoftware. Figure 1 depicts the set of impedance plots observed for (a) $\mathrm{PEO} / \mathrm{PVP} / \mathrm{KI} / \mathrm{I}_{2}$ and (b) $\mathrm{PEO} / \mathrm{PVP} / \mathrm{KI} / \mathrm{I}_{2} / 0.03 \mathrm{M}$ pyrazole thin film specimens. The ionic conductivity $(\sigma)$ value of pure $\mathrm{PEO}$ is found to be $1.3 \times 10^{-8} \mathrm{Scm}^{-1}$ at room temperature and for the pure blended $\mathrm{PEO} / \mathrm{PVP}$ films $\sigma$ value is observed to be $4.08 \times 10^{-8} \mathrm{Scm}^{-1}$ thus inferring that this trivial increase in the value of $\sigma$ may be due to the presence of PVP which is acting as a plasticizer ${ }^{3}$. 


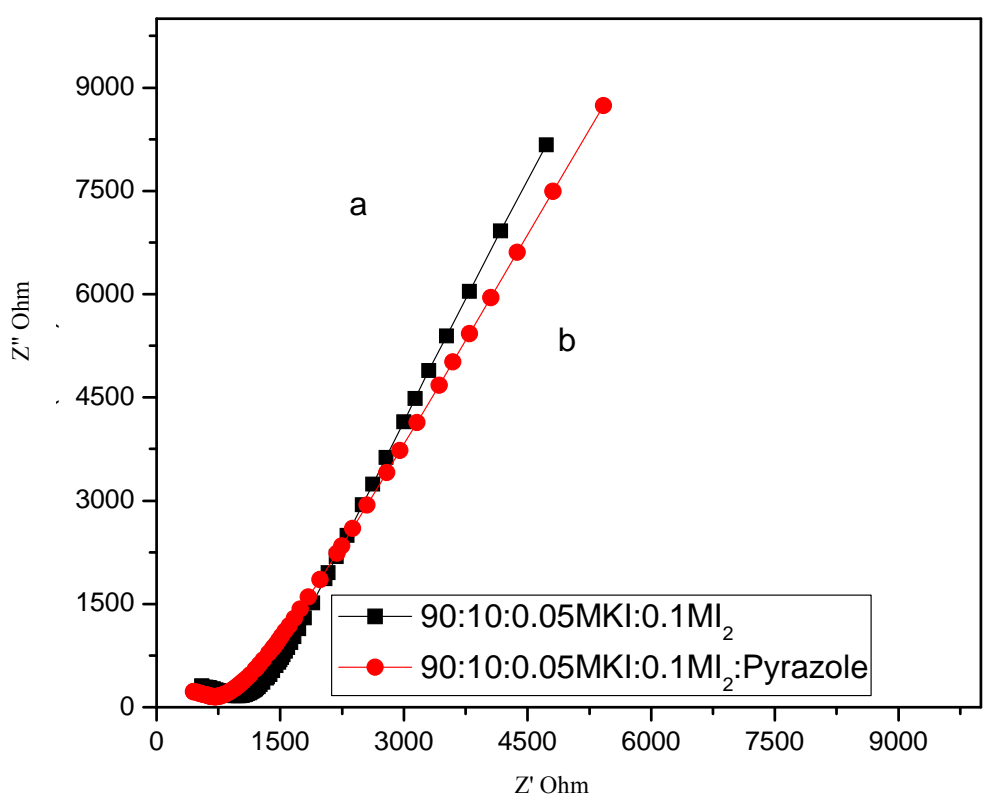

Figure 1. Impedance plots obtained for (a) $\mathrm{PEO} / \mathrm{PVP} / \mathrm{KI} / \mathrm{I}_{2}$ polymer and (b) $\mathrm{PEO} / \mathrm{PVP} /$ $\mathrm{KI} / \mathrm{I}_{2} /$ Pyrazole

The importance of adding a nitrogenous compound like pyrazole into the polymer matrix is to provide a charge transfer complex in conjunction with $\mathrm{KI}$ and $\mathrm{I}_{2}$ and enhance the segmental motion of the polymer matrix ${ }^{4}$. During the present study the value of room temperature ionic conductivity has been found to be enhanced by two orders of magnitude to $8.46 \times 10^{-6} \mathrm{Scm}^{-1}$ with addition of pyrazole into the $\mathrm{PEO} / \mathrm{PVP} / \mathrm{KI} / \mathrm{I}_{2}$ matrix.

\section{Differential scanning calorimentry(DSC) studies}

The DSC curves for observed pure $\mathrm{PEO} / \mathrm{PVP}$ blend and $\mathrm{PEO} / \mathrm{PVP} / \mathrm{KI} / \mathrm{I}_{2}$ complex and $\mathrm{PEO} / \mathrm{PVP} / \mathrm{KI} / \mathrm{I}_{2} / 0.03 \mathrm{M}$ pyrazole polymer electrolyte systemare given in Figure 2 . The degree crystallinity was calculated from the DSC result using the relation,

$$
X_{c}=\frac{\Delta H_{m}}{\Delta H_{m}}
$$

The melting temperature $\left(\mathrm{T}_{\mathrm{m}}\right)$, melting enthalpy $\left(\Delta \mathrm{H}_{\mathrm{m}}\right)$ and degree of crystallinity $\left(\chi_{\mathrm{c}}\right)$ values were determined from these plots and the values are listed in Table $1 . \Delta \mathrm{H}_{\mathrm{m}}$ is the pure melting temperature of PVP which is nearly ${ }^{5} 179^{\circ} \mathrm{Jg}^{-1}$. The DSC thermogram of PEO/PVP as shown in Figure 2(a) shows a sharp and intense curve and occurrence of the melting temperatureat $127{ }^{\circ} \mathrm{C}$, there by exhibiting a considerable degree of crystallinity. The $\mathrm{T}_{\mathrm{m}}$ value of $\mathrm{PEO} / \mathrm{PVP} / \mathrm{KI} / \mathrm{I}_{2}$ is found to be $96.1{ }^{\circ} \mathrm{C}$ which tends to support the conductivity result where PVP being an amorphous polymer considerably brings down the crystallinity of PEO phase. However, the melting temperature observed for the polymer electrolyte $\mathrm{PEO} / \mathrm{PVP} / \mathrm{KI} / \mathrm{I}_{2} /$ pyrazole is apparently lowered to $67.8^{\circ} \mathrm{C}$ which may be probably related to the most probable coordination of $\mathrm{PEO} / \mathrm{PVP}$ with pyrazole that may eventually result in lowering of the degree of crystallinity for pure PEO/PVP from 32.9 to $22.7 \%$ for $\mathrm{PEO} / \mathrm{PVP} / \mathrm{KI} / \mathrm{I}_{2} /$ pyrazole as revealed form Table 1 . 


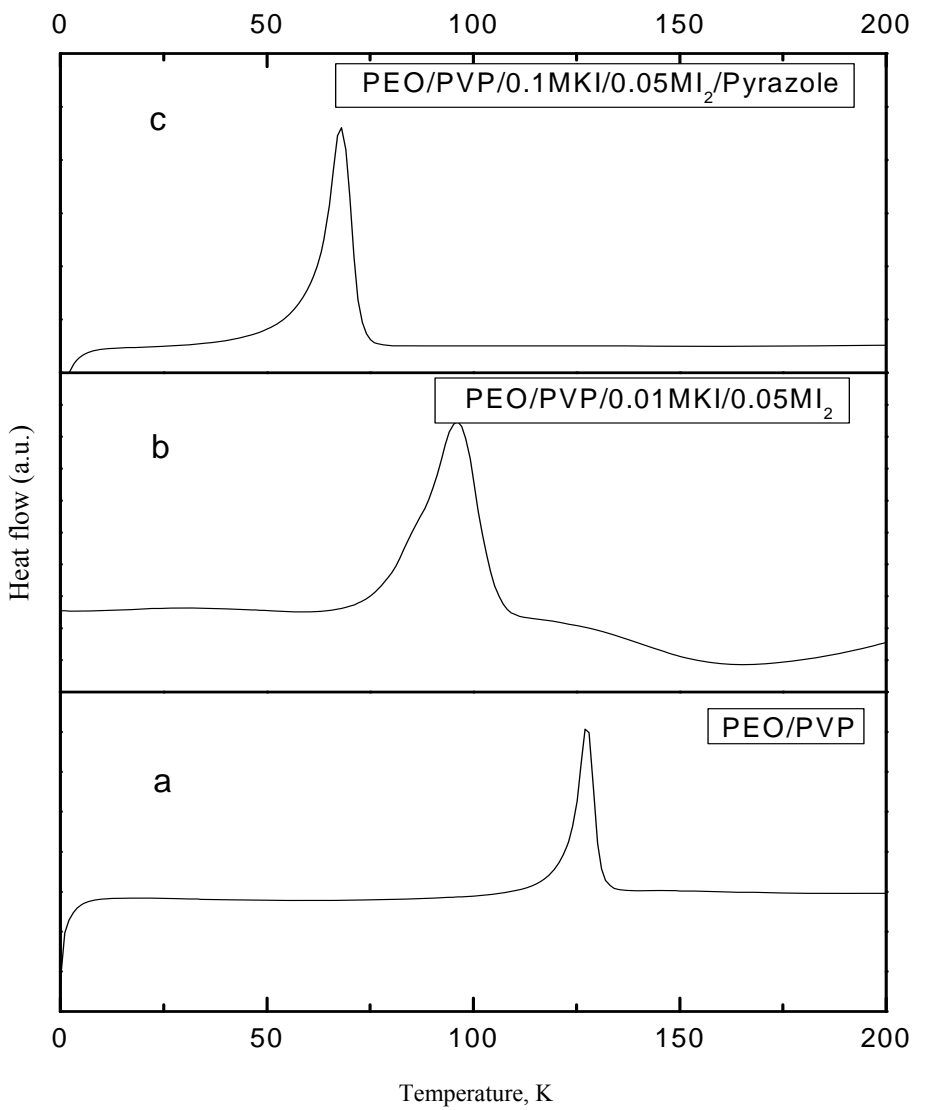

Figure 2. Differential scanning calorimetric curves of (a) PEO/PVP (b) PEO-PVP$\mathrm{KI}_{2} \mathrm{I}_{2}$ (c) $\mathrm{PEO} / \mathrm{PVP} / \mathrm{KI} / \mathrm{I}_{2} /$ pyrazole

Table 1. Thermal parameters derived for PEO/PVP, PEO/PVP/KI $/ \mathrm{I}_{2}$ and $\mathrm{PEO} / \mathrm{PVP} / \mathrm{KI} / \mathrm{I}_{2} /$ pyrazolepolymer electrolytes

\begin{tabular}{cccc}
\hline System & $\begin{array}{c}\text { Melting temperature, } \\
\mathrm{T}_{\mathrm{m}},{ }^{\circ} \mathrm{C}\end{array}$ & $\begin{array}{c}\text { Melting enthalpy, } \\
\Delta \mathrm{H}_{\mathrm{m}}, \mathrm{Jg}^{-1}\end{array}$ & $\begin{array}{c}\text { Degree of } \\
\text { crystallinity, } \chi_{\mathrm{c}} \\
\%\end{array}$ \\
\hline PEO-PVP & 127.5 & 58.94 & 32.9 \\
$\begin{array}{c}\text { PEO-PVP-0.05 M } \\
\text { KI-0.1 M I }\end{array}$ & 96.1 & 52.61 & 29.4 \\
$\begin{array}{c}\text { PEO-PVP-0.05 M } \\
\text { KI-0.1 M I } \mathrm{M}_{2}-0.03 \mathrm{M} \text { Pyrazole }\end{array}$ & 67.8 & 40.7 & 22.7 \\
\hline
\end{tabular}

\section{$X$-ray diffraction $(X R D)$ data}

The X-ray diffraction results have been used to confirm the feasibility of complexation of polymer blend chosen with the dopant material namely pyrazole. From Figure 3 it is evident that characteristic peaks for PEO and PVP are observed at $2 \theta=19,23^{\circ}$ and $2 \theta=11,20^{\circ}$ respectively. The set of sharp peaks that are observed appear to support thecrystalline nature 
of PEO whereas those humps that are present would correspond to the amorphous nature of PVP polymer. The blended polymer matrix exhibits a reduction in intensity of the crystalline peaks of PEO which is evident in Figure 3(e) which may be due to the addition of pyrazole into the blended matrix. These results may be associated with Hodge et al., principle which establishes acorelation between the height of the diffraction peak and extent of crystallinity ${ }^{6}$. The above results thus suggest that as the content of amorphous nature increases the ionic mobility is expected to increase as confirmed by the conductivity studies.

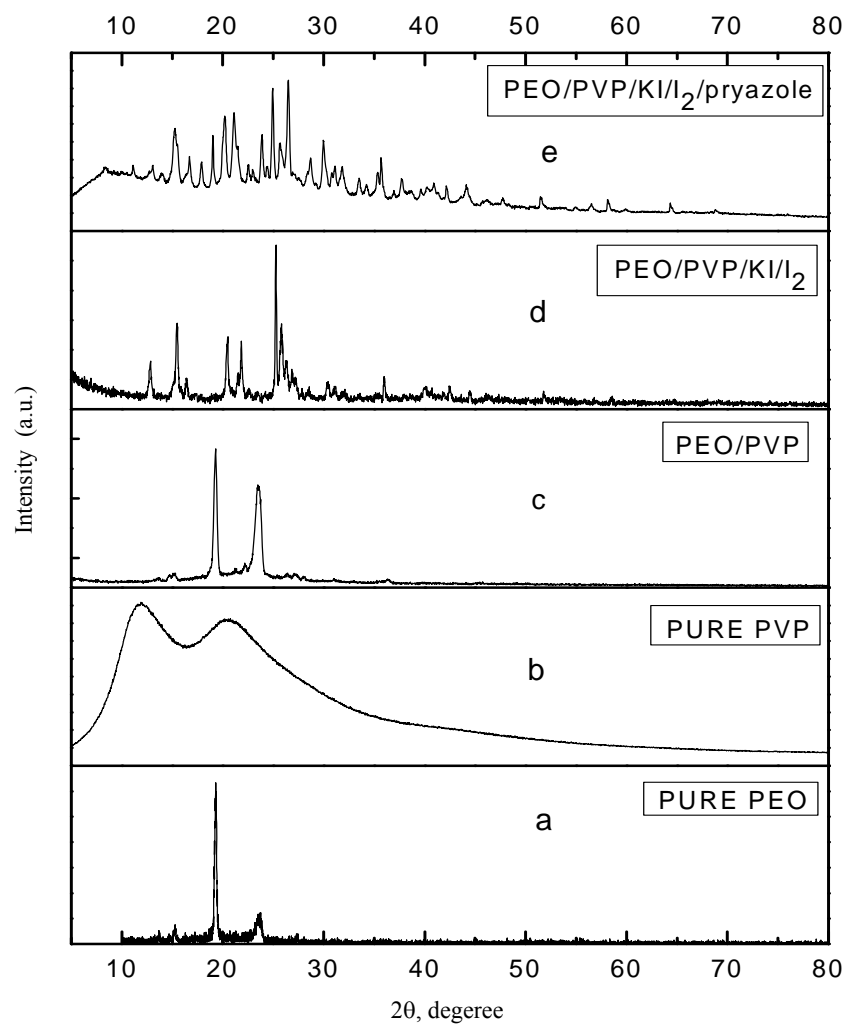

Figure 3. XRD patterns of (a) pure PEO (b) pure PVP (c) $\mathrm{PEO} / \mathrm{PVP}$ (d) $\mathrm{PEO} / \mathrm{PVP} / \mathrm{KI} / \mathrm{I}_{2}$ (e) $\mathrm{PEO} / \mathrm{PVP} / \mathrm{KI} / \mathrm{I}_{2} /$ pyrazolepolymer

\section{Fourier tranform infrared spectroscopy (FTIR) results}

The most frequently performed observations to confirm the complexation of the polymer host with dopant involve variation in intensity of the bands, shifting of the bands with respective to the dopant content and appearance of new bands due to the presence of salt content in the polymer host $^{6}$. The FTIR spectrum for the specimen ofpristine $\mathrm{PEO} / \mathrm{PVP} / \mathrm{KI} / \mathrm{I}_{2} / 0.03 \mathrm{M}$ pyrazole, recorded between 4000 and $400 \mathrm{~cm}^{-1}$ is shown in Figure 4.

\section{PEO confirmation}

The absorption band observed at $1349 \mathrm{~cm}^{-1}$, corresponds to $\mathrm{CH}_{2}$ bending of $\mathrm{PEO}$, while the band at $935 \mathrm{~cm}^{-1}$ may be assigned to the $\mathrm{CH}_{2}$ rocking vibrations of the ethylene group. Another band noticed at $832 \mathrm{~cm}^{-1}$ may be assigned to helical structure of PEO whereas the typical band at $1445 \mathrm{~cm}^{-1}$ is ascribed to the $\mathrm{CH}_{2}$ scissoring mode of $\mathrm{PEO}$ matrix. 


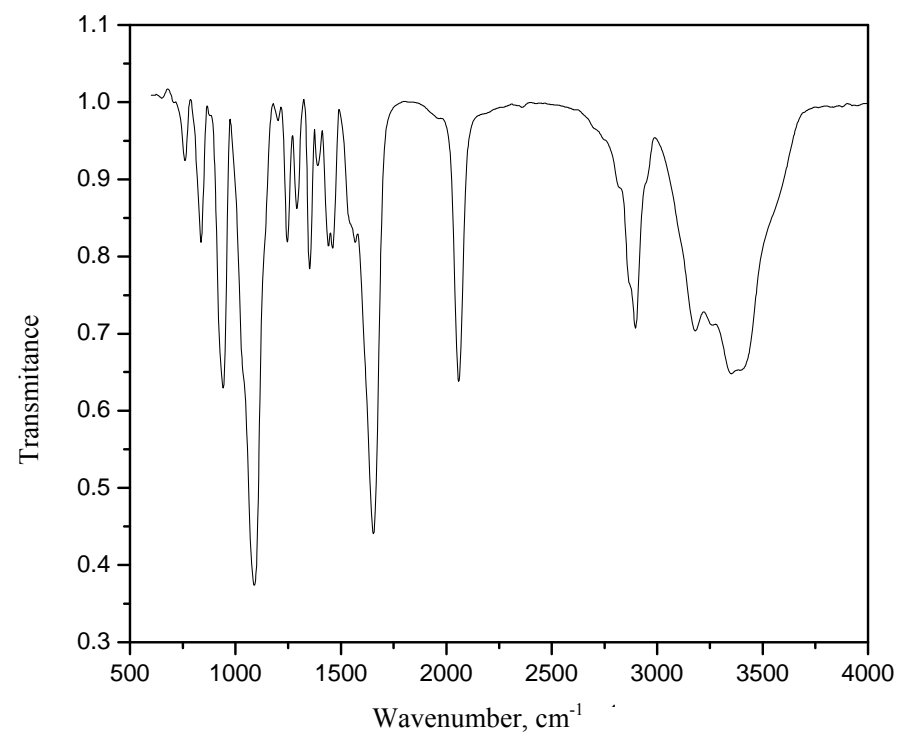

Figure 4. FTIR spectrum recorded for $\mathrm{PEO} / \mathrm{PVP} / \mathrm{KI} / \mathrm{I}_{2} /$ pyrazole

\section{PVP confirmation}

The characteristic vibrational band observed at $2897 \mathrm{~cm}^{-1}$ may be attributed to the aliphatic $\mathrm{CH}$ stretching of PVP matrix whereas the typical band appearing in $3406 \mathrm{~cm}^{-1}$ confirms the presence of PVP polymer. It is interesting to note that the vibrational band appearing at $1243 \mathrm{~cm}^{-1}$ corresponds to the $\mathrm{CH}_{2}$ twisting or wagging of both PEO and PVP chains. On the other hand stretching vibrations of C-N in PVP is present ${ }^{7}$ at $1082 \mathrm{~cm}^{-1}$.

\section{Complexation of $\mathrm{PEO} / \mathrm{PVP} / \mathrm{KI} / \mathrm{I}_{2} /$ pyrazole}

The $\mathrm{C}-\mathrm{O}-\mathrm{C}$ stretching modes sen around the region 1111 to $1115 \mathrm{~cm}^{-1}$ may be ascribed as due to the complexation of ether oxygenwith $\mathrm{K}^{+}$ion. The Shift in band positions was also observed, which confirms the complexation when plasticizer was added to the PEO/PVP martrix. Further more the $\mathrm{C}-\mathrm{H}$ bending of $\mathrm{CH}_{2}$ in both $\mathrm{PEO}$ and PVP polymers appearing at $1483 \mathrm{~cm}^{-1}$ was shifted gradually towards $1441 \mathrm{~cm}^{-1}$ The characteristic vibration band at $1051 \mathrm{~cm}^{-1}$ of pure blend assigned to $\mathrm{C}-\mathrm{O}$ stretching of PEO was also found to get shifted to $1088 \mathrm{~cm}^{-1}$. These changes are in good agreement with the spectral behaviour of $\mathrm{PEO} / \mathrm{KI} / \mathrm{I}_{2}$ complex and are associated with the increase in the number of gauche conformers along the PEO chain ${ }^{8}$

\section{Conclusion}

The $\mathrm{PEO} / \mathrm{PVP} / \mathrm{KI} / \mathrm{I}_{2}$ based soild polymer electrolyte system incorporated with $0.03 \mathrm{M}$ of nitrogenous dopant pyrazolewas prepared using solution casting technique. The room temprature ionic conductivity of $\mathrm{PEO} / \mathrm{PVP} / \mathrm{KI} / \mathrm{I}_{2}$ polymer electrolyte doped with pyrazole has witnessed two orders of magnitude enhancement compared to that of the undoped polymer. The present XRD studies have shown the disordered crystalline structure of $\mathrm{PEO} / \mathrm{PVP}$ occuring due to the addition of dopant pyrazole as whereas the DSC studies of the polymer blend electrolyte with pyrazole have clearly demonstrated that because of the interaction between the pyrazole and blended polymes a depression of the melting 
temperature and melting enthalpy of the polymer blend take place. The FTIR studies of these blends have revealed the presence of strong interaction of pyrazole with $\mathrm{PEO} / \mathrm{PVP} / \mathrm{KI} / \mathrm{I}_{2}$ matrix which results in the miscibility of pyrazole with $\mathrm{PEO} / \mathrm{PVP}$. From the above results it is inferred that obtained the chosen polymer electrolyte may be suitable for an all solid-state electrochemical devices.

\section{Acknowledgment}

The authors are thankful to University Grants Commision, New Delhi for the financial support received in the form of a research grant under University with Potential for Excellence scheme.

\section{References}

1. Agrawal R C and Pandey G P, J Phys D:Appl Phys., 2008, 41 ,1-18.

2. Kusama H and Arakawa H, Sol Energy Mater Sol Cells, 2004, 81(1), 87-99; DOI:10.1016/j.solmat.2003.09.001

3. Wu J H, li PJ, Hao S C, Yang H X and Lan Z, Electrochim Acta, 2007, 52(17), 53345338; DOI:10.1016/j.electacta.2006.12.067

4. Ganesan S, Muthuraaman B, Vinod Mathew, Kumara Vadivel M, Maruthamuthu P, Ashokkumar M and Austin Suthanthiraraj S, Electrochim Acta, 2011, 56(24), 88118817; DOI:10.1016/j.electacta.2011.07.081

5. Saroj A L, Singh R K and Chandra S, Mater Sci Engg B, 2013, 178(4), 231-238; DOI:10.1016/j.mseb.2012.11.007

6. Hodge R M, Edward G H and Simon G P, Polymer, 1996, 37(8), 1371-1376; DOI:10.1016/0032-3861(96)81134-7

7. KiranKumar K, Ravi M, Pavani Y, Bhavani S, Sharma A K and Narasimha Rao V V R, Physica B, 2011, 406(9), 1706-1712; DOI:10.1016/j.physb.2011.02.010

8. Muthuraaman B and Maruthamuthu P, Electrochimica Acta, 2011, 56(15), 54055409; DOI:10.1016/j.electacta.2011.02.112 